\title{
Mapas cognitivos e a pesquisa organizacional: explorando aspectos metodológicos
}

\author{
Antonio Virgílio Bittencourt Bastos \\ Universidade Federal da Bahia
}

\begin{abstract}
Resumo
A intersecção entre as ciências da cognição e os estudos organizacionais criou um campo emergente de pesquisa denominado cognição organizacional. Tal campo se apóia em uma visão de organização como processos socialmente construídos que, de forma recorrente, articulam atores em interação. Assim, grande ênfase é dada ao papel das cognições dos atores como mediadoras de importantes processos e produtos organizacionais, em seus diferentes níveis. Os mapas cognitivos, nesse domínio, têm sido crescentemente utilizados como ferramentas para representar estruturas e processos cognitivos que ajudam a compreender decisões e ações que configuram uma organização. O presente texto, apoiado em uma revisão da literatura, após localizar as tendências no campo que justificam o uso dos mapas cognitivos, procura caracterizá-los, especialmente no tocante às decisões metodológicas que configuram seus diferentes tipos. Como conclusão, discutem-se os limites e potencialidades dos mapas cognitivos como ferramentas de pesquisa de processos organizacionais.
\end{abstract}

Palavras-chave: Cognição, Organização, Mapas cognitivos, Mapas causais.

\begin{abstract}
Cognitive maps and organizational research: exploring methodological issues. The intersection between cognitive sciences and organizational studies has created a new field of research called organizational cognition. Research in this field is based on a view of organizational processes as the result of social constructions - the exchange and articulation of ideas among those involved in the organization. Thus, a great emphasis is given to the role of the actor's cognitions, which mediate important organizational processes and products. Cognitive maps have been increasingly used in this domain as tools to represent the cognitive structures and processes that help to understand the decisions and actions that define an organization. The present text first identifies the research objectives that justify the use of cognitive maps, then characterizes these tools based on the methodological issues that differentiate among various approaches. The third and final topic addressed involves a discussion of the limits and potentialities of cognitive maps as research tools in the study of organizational processes.
\end{abstract}

Key words: Cognition, Organization, Cognitive Maps, Causal Maps

$\mathrm{O}$ s estudos organizacionais - quer na sua vertente microorientada, quer no campo das teorias macroorganizacionais - passam por importantes transições na forma como o próprio fenômeno rotulado 'organização' tem sido conceituado. O esforço investido na redefinição deste conceito tem o poder de gerar desdobramentos importantes, tanto no entendimento ou explicação de aspectos substantivos deste complexo fenômeno quanto, o que mais nos interessa no presente momento, nos aspectos metodológicos relacionados às estratégias usuais para investigá-lo.
Algumas dessas mudanças foram importantes para chegar num entender atual de organizações como produtos de um processo de construção social, em que se insere a nossa preocupação com o uso dos mapas cognitivos, os quais servem como instrumentos no estudo do comportamento macro e microorganizacional.

Como discutido em trabalho anterior (Bastos, 2000a), duas tensões marcam a trajetória dos estudos organizacionais no tocante ao status ontológico do fenômeno 'organização'. A primeira tensão baseia-se no conflito entre entendimentos diferentes do que é uma organização: ora uma entidade, 
ora um processo. A segunda tensão refere-se à explicação dos fenômenos organizacionais: se estes estão determinados pelas ações individuais, ou se ações individuais são produto de fenômenos organizacionais. Ou seja, a primazia estaria nos indivíduos ou nas organizações, enquanto agentes causais?

No momento presente, verifica-se uma crescente tendência a ver as organizações como um fenômeno processual (Rousseau, 1997), fortemente enraizado nas ações e decisões de pessoas, fortalecendo-se uma vertente de pensamento que, desde Barnard (1979), Simon (1945/1979) e March e Simon (1956/1981), recusa-se a reificar a organização e coloca as pessoas, os grupos, as redes sociais, as cognições gerenciais e os processos decisórios como alicerces do fenômeno organizacional.

Tal tendência revela-se congruente com a importância crescente de um paradigma interpretante (Burrel \& Morgan, 1982), que pressupõe que mesmo os aspectos mais tangíveis da vida organizacional envolvem construções dos indivíduos que as constituem. É congruente, portanto, com o avanço de uma epistemologia construcionista ou social construtivista que leva a se ver a organização como uma 'construção social' (Porac, Meind \& Stubbart, 1996) ${ }^{1}$. Para Wilpert (1995), olhar o fenômeno organizacional como sendo socialmente construído através da interação entre atores relevantes está entre as importantes mudanças que caracterizam o mundo do trabalho, no campo teórico. Assim, os mitos, rituais, fofocas, estórias, símbolos, estruturas negociadas/construídas e metas visionárias fornecem a base de valores e significados compartilhados que sustentam uma organização (Wilpert, 1995). Para Weick e Bougon (1986), as "organizações existem, largamente, na mente e sua existência toma a forma de mapas cognitivos" (p. 102).

Como nos afirma Weick (1993), ao analisar a organização como uma 'mente coletiva', ela não é uma entidade concreta, tangível e pairando acima e fora dos indivíduos que a compõem. Deve ser vista como um conjunto de disposições, uma capacidade para gerar ações, que reside em cada individuo, porém interconectada e modulada por ações de outras pessoas. Para Weick (1973), "os comportamentos interligados são os elementos básicos que constituem qualquer organização" (p. 91).

Esse novo entendimento das organizações guarda uma estreita relação com a importância assumida pela perspectiva cognitivista como já assinalaram vários autores (Ilgen \& Klein, 1988; Rousseau, 1997; Wilpert, 1995). Como se percebe claramente, uma ênfase importante vem sendo atribuída aos atores e aos processos de produção de conhecimentos que constroóem o sentido de "organização". Para Porac et al. (1996), "esse interesse é consistente com a ênfase cognitiva comum nas ciências sociais nas três décadas pas- sadas, quando pesquisadores em muitas disciplinas têm voltado sua atenção para os aspectos epistemológicos, representacionais e construídos da vida social" (p. 9).

Há, no campo do comportamento microorganizacional, uma forte tradição de uso de conceitos cognitivos para compreender, entre outros, fenômenos como processamento de informações, definição de problemas, estruturação cognitiva como afetando as percepções do trabalho, a motivação, a tomada de decisão, liderança e avaliação de desempenho. Revisões da área (Ilgen \& Klein, 1988; Lord \& Maher, 1989, 1991; Tenbrunsel, Galvin, Neale \& Bazerman, 1999) revelam que uma abordagem cognitivista sempre ocupara um locus próprio nos estudos de processos microorganizacionais. Mesmo assim, Katzell (1991) inclui a 'perspectiva cognitivista' como uma das doze macrotendências identificadas no campo da Psicologia Organizacional e Industrial $^{2}$, campo que mais contribui para a compreensão dos processos microorganizacionais.

O impacto de uma abordagem cognitivista nos estudos organizacionais, todavia, se tornou mais visível quando tópicos tradicionais de Teoria das Organizações passaram a ser abordados através de conceitos e estratégias metodológicas até então fortemente enraizadas na vertente de estudos microorganizacionais. Walsh (1995) oferece uma ampla revisão da pesquisa na área de cognição gerencial e organizacional, revelando como tal fenômeno vem sendo apreendido em diferentes níveis de análise - indivíduo, grupo, organização e indústria. $\mathrm{O}$ funcionamento do cérebro como uma metáfora para o funcionamento das organizações (Morgan, 1996) já revela a consolidação de um campo específico que articula cognição, gestão e organização. O termo 'cognição organizacional' é, de forma ampla, aplicado ao campo de estudos que, apoiado em uma perspectiva cognitivista, investiga como indivíduos e organizações constróem os seus ambientes e como tais processos se relacionam com importantes produtos organizacionais.

As mudanças que configuram essa forma nova de entender e analisar as organizações colocam importantes desafios para os pesquisadores. Entre estes, a clara exigência de desenvolver estratégias metodológicas mais sensíveis e adequadas à natureza dos fenômenos organizacionais como 'construções sociais' ou como estruturas e processos de conhecimento que articulam cognição e ação dos membros organizacionais. Uma resposta a esta necessidade foi a crescente utilização do conceito de mapas cognitivos com uma função explanativa de como os indivíduos estruturam e organizam as suas cognições e como estas afetam as suas decisões e ações.

O presente trabalho tem como objetivo central discutir o uso dos "mapas cognitivos" enquanto ferramentas de pesquisa em organizações. Para tanto, partimos de uma defini- 
ção dos mapas cognitivos, com ênfase para o seu uso na pesquisa organizacional. Em seguida, descrevemos alguns tipos específicos de técnicas de mapeamento, em termos das diferenças metodológicas envolvidas na sua aplicação. Alguns exemplos de pesquisa são apresentados para ilustrar a variedade com que essa ferramenta de pesquisa está sendo utilizada. Como conclusão, discutimos o potencial desta estratégia em contribuir para o avanço teórico no campo, buscando identificar domínios em que o seu uso poderia ser incrementado.

\section{Mapas cognitivos: o que são?}

Os experimentos clássicos de aprendizagem em labirinto conduzidos por E. Tolman introduzem, no âmbito da Psicologia, o conceito de mapa cognitivo. Nessa sua primeira formulação, os mapas eram representações de indícios visuais, táteis, auditivos, que configuram o ambiente e permitem a localização do sujeito no espaço. Ou seja, um conceito mediador que ajudava a explicar a diferença de desempenho entre animais familiarizados, ou não, com os labirintos. Csányi (1995), apoiado em estudos etológicos, revela que a quase totalidade dos animais utiliza mapas cognitivos para se orientar. Esses mapas não são, ressalta o autor, representações estáticas do ambiente e sim, "modelos dinâmicos de várias características, eventos e processos que influenciam a sobrevivência do animal" (p. 24).

Assim, o termo mapa cognitivo refere-se "ao processo pelo qual um organismo representa o ambiente em seu próprio cérebro, uma atividade que os cientistas do cérebro mais contemporâneos parecem concordar como sendo uma da principais funções do cérebro" (Laszlo, Masulli, Artigiani \& Csányi, 1995). Os mapas envolvem, portanto, conceitos e relações entre conceitos que são utilizados pelos sujeitos para compreender o seu ambiente e dar-lhe sentido.

Como bem destaca Csányi (1995), quando falamos de mapas construídos pelos seres humanos, temos de considerar o ambiente físico apenas como uma parte dos mapas construídos. O mais importante é que a competência lingüística ou a linguagem modifica o meio pelo qual o ambiente é mapeado. O mapeamento deixa de ser perceptual e, portanto, dependente da experiência direta do indivíduo e passa a ser um mapeamento lingüístico, um mapeamento de conceitos. Neste, podemos aceitar e transferir descrições e prescrições de outros indivíduos, prescindindo de uma experiência direta. A comunicação lingüística permite que as pessoas, em grupo, troquem segmentos dos seus modelos e, neste sentido, que os conceitos individuais se tornem parte de uma estrutura coletiva de ordem superior, que pode ser identificada como cultura (Csányi,1995). São todas essas possibilidades permitidas pela linguagem que fazem com que os mapas cognitivos humanos sejam realidades social- mente construídas. Algumas características são importantes para uma compreensão mais precisa do conceito de mapa cognitivo.

Os mapas não são representações estáticas do ambiente, sendo sempre atualizados a partir das experiências do sujeito. A necessidade de um contínuo ajustamento às mudanças do contexto impõe a exigência de incorporação de novas informações e, portanto, os mapas vão sendo reconstruídos pelo processo de aprendizagem.

Em segundo lugar, os mapas não consistem em uma cópia exata do ambiente, mas sim uma representação ou modelo simplificado da realidade que fornece uma imagem aproximada desta realidade ${ }^{4}$ (Laszlo et al., 1995). O mapa é resultado de um processo de abstração, cerne da atividade simbólica, o que envolve seleção, omissão, desconsideração de diferenças e organização de detalhes da realidade de modo que a pessoa possa construir um mundo coerente, estável e organizado, enquanto uma totalidade. Esse processo é impreciso, não só porque a realidade está sempre em mudança, mas também pela natureza inferencial dos mecanismos envolvidos neste processo.

Uma terceira característica reporta-se ao fato de que os mapas estruturam as regularidades percebidas pelos sujeitos ao explorarem os seus ambientes, funcionando como estruturas epistemológicas (Weick \& Bougon, 1986) que norteiam a ação da pessoa. Assim, eles são flexíveis (podendo ser atualizados a todo momento) e são utilizados para perceber relações entre comportamentos variados e resultados semelhantes (quando se observa, por exemplo, que a pessoa entende que existam pontos de partida alternativos e caminhos alternativos para atingir um mesmo objetivo) ${ }^{5}$.

Vejamos, então, algumas tentativas de precisar o conceito de mapa cognitivo.

Para Bougon (1983), mapa cognitivo é um termo usado de forma bastante genérica para representar possíveis padrões de relações entre conceitos. As palavras e frases que os indivíduos enunciam para expressar idéias ou conceitos em um dado contexto constituem os blocos para a construção do mapa cognitivo.

Os mapas cognitivos são representações, schemas ou modelos mentais construídos pelos indivíduos, a partir das suas interações e aprendizagens em um domínio específico do seu ambiente, e que cumprem a função de dar sentido à realidade e permitem-lhes lidar com os problemas e desafios que esta lhes apresenta (Swan, 1997).

Este mesmo autor diferencia os mapas das técnicas de mapeamento. O mapeamento cognitivo é entendido como o conjunto de técnicas ou ferramentas de pesquisa voltadas para identificar os elementos que integram esses mapas ou modelos construídos pelos indivíduos e partilhados, em maior ou menor grau, por outros indivíduos. Essas técnicas envol- 
vem formas de retratar graficamente as crenças subjetivas acessadas, permitindo a visualização das relações significativas identificadas.

Pensando nos procedimentos usados e produtos gerados por pesquisadores para captar os mapas dos seus sujeitos, Cossette e Audet (1994) propõem a seguinte definição: "um mapa cognitivo é uma representação gráfica da representação mental que o pesquisador faz de um conjunto de representações discursivas enunciadas por um sujeito a partir de suas próprias representações cognitivas, a propósito de um objeto particular" (p. 15).

Algumas noções são importantes para entendermos os mapas a partir da definição acima.

Primeira, o pesquisador tem acesso ao material verbal produzido pelo sujeito que resulta do processo de "schematização" através do qual ele conceitua a situação em que se encontra. Segunda, tanto a "schematização" como os elementos argumentativos que marcam o discurso construído são parciais, pois os indivíduos revelam aquilo que é útil aos seus objetivos e simplificam a realidade em função dos seus limites cognitivos. Finalmente, esse discurso é um produto semiótico, logo é contextual e não consiste na expressão de uma realidade objetiva; ele, no entanto, organiza as suas representações de acordo com as regras da lógica natural, possuindo um caráter persuasivo e pragmático.

Como afirma Laukkanen (1992), os mapas seriam uma das alternativas de ferramentas para representar dados verbais (informações orais ou escritas que expressam afirmações, predições, explanações, argumentos, regras) através dos quais temos acesso a representações internas e a elementos cognitivos (imagens, conceitos, crenças causais, teorias, heurísticas, regras, scripts etc.). Nesse sentido, os mapas podem dar acesso a pressupostos do respondente, mesmo quando estes não são visíveis para o próprio participante. Uma comparação dos mapas de pessoas que dividem um mesmo contexto também permite identificar estruturas conceituais partilhadas entre indivíduos.

Essa mesma perspectiva, que toma o mapa como uma das estratégias possíveis para representar cognições sociais, encontramos em Nicolini (1999): "mapas poderiam ser considerados apenas instrumentos de descrição e representação que ajudam na discussão e análise de alguns modos de pensamento e explicação dos eventos" (p. 836). A tarefa de mapear estruturas cognitivas envolveria, segundo o mesmo autor, "explorar as maneiras pelas quais essas entidades representacionais são unidas, transformadas ou contrastadas" (p. 836).

As experiências que as pessoas desenvolvem em ambientes organizacionais também são estruturadas em padrões pessoais de conhecimento, que podem ser chamados de mapas cognitivos, e que são utilizados para compreender as situações organizacionais e lidar com elas. Em decorrência, os mapas cognitivos têm sido utilizados, em diversos domínios organizacionais, dentro de um quadro de referência mais geral, o qual busca identificar estruturas de conhecimento que guiam a percepção, julgamento e decisões, tanto em nível de indivíduos (sobretudo executivos e gestores), como de grupo, da organização e de grupos de organizações.

No campo organizacional, dentre muitos fenômenos, dois se destacam pela quantidade de estudos que utilizam técnicas de mapeamento cognitivo:

- O primeiro, domínio de maior utilização, refere-se ao pensamento e formulação de estratégia. Huff (1990) apresenta uma importante sistematização sobre diferentes tipos de mapas cognitivos e reúne trabalhos que utilizam tal ferramenta na análise do pensamento estratégico. Nesse campo, os mapas têm sido utilizados para explorar a visão estratégica de executivos centrais, para compreender o processo de formulação de estratégias e suas mudanças com o tempo, para analisar a interpretação do ambiente (como seus elementos são selecionados, categorizados e avaliados) e entender como as empresas identificam vantagens competitivas.

- O segundo, um domínio correlato ao da estratégia, envolve o levantamento de mapas para analisar processos de inovação tecnológica, a exemplo do estudo de Swan e Newel (1998) que exploraram, entre 16 executivos de uma empresa canadense, a dinâmica social e política no processo de construção de sentido das inovações tecnológicas.

\section{Mapas cognitivos nos estudos} organizacionais: diferentes metodologias de

$$
\text { construção }
$$

Tendo em vista o objetivo central do presente texto - a discussão de peculiaridades metodológicas que tornam as técnicas de mapeamento cognitivo uma ferramenta particularmente útil para investigar processos organizacionais na sua dimensão simbólica, comunicativa e hermenêutica - a seguir, após uma rápida apresentação dos diferentes tipos de mapas, vamos examinar alguns exemplos pontuais de pesquisas que utilizaram esse recurso, de forma a explicitar as decisões metodológicas e técnicas subjacentes.

O exame da literatura organizacional que utiliza mapas cognitivos revela, de imediato, uma importante característica: a pluralidade de formas de sua apresentação ou tratamento gráfico. Essa diversidade se estende, também, aos caminhos envolvidos na sua construção, às fontes de dados utilizadas e às estratégias de análise empregadas. Ou seja, 'mapa cognitivo' é um rótulo bastante amplo que engloba procedimentos muito diversificados de descrever e representar graficamente cognições ou informações e conheci- 
mentos que as pessoas acessam para dar sentido a eventos, lidar com problemas e fundamentar suas decisões e ações.

Buscando ordenar essa diversidade, Huff (1990) reúne os mapas cognitivos em cinco grandes grupos, em um contínuo quanto ao nível de interpretação envolvido na sua construção. Em um extremo, temos os mapas que avaliam atenção, associação e importância de conteúdos cognitivos e que se detêm no material manifesto; no outro extremo, temos os mapas que especificam schemas, enquadramentos e códigos perceptuais com elevado grau de interpretação por parte do pesquisador. Entre estes dois extremos, estão os mapas que descrevem categorias e taxionomias, os mapas causais e os mapas que descrevem a estrutura de raciocínio e decisão.

Em um trabalho posterior, Fiol e Huff (1992) destacam três alternativas de mapeamento mais usadas na pesquisa organizacional, voltadas para três diferentes aspectos dos processos cognitivos: (a) os mapas de identidade, por identificarem os principais atores, eventos e processos do "terreno"; (b) os mapas de categorização, voltados para as relações entre tais entidades e, (c) mapas causais e de argumentação, centrados no raciocínio causal que liga entidades ao longo do tempo, ou no raciocínio que embasa decisões. $\mathrm{Na}$ Tabela 1, as características que definem cada tipo de mapa são destacadas, de forma a permitir uma visão geral dos elementos que os aproximam e os afastam.

Partindo desse painel geral, uma síntese dos elementos metodológicos que caracterizam esses tipos básicos de mapas cognitivos é apresentada a seguir. Sem perder o foco nas questões metodológicas envolvidas, procuramos ilustrar cada categoria com um exemplo de pesquisa, preferencialmente desenvolvida no Brasil.

\section{a) Mapas de identidade}

Os mapas de identidade constituem, na realidade, o padrão básico e ponto de partida para os demais tipos. Eles permitem descrever o "terreno cognitivo" (Fiol \& Huff, 1992) ao identificarem os conceitos que as pessoas recuperam para estruturar a sua compreensão de um problema ou domínio particular. Nesse sentido, os mapas de identidade estão implícitos nos demais tipos de mapeamento e, portanto, constituem importantes filtros através dos quais as pessoas dão sentido ao seu contexto.

A simples freqüência com que os conceitos são usados e o seu agrupamento em temas fornecem importantes elementos sobre a centralidade cognitiva. Tanto ao longo de um texto como de um relato verbal, a identificação de mudanças de temas, ou da justaposição de conceitos também pode sugerir mudanças no foco de atenção ou indicar as conexões que o sujeito faz.

Em termos metodológicos podemos afirmar: (a) A operação básica aproxima-se da análise qualitativa de conteúdos verbais. O processo mais simples envolve a criação de categorias e a sua contagem. Estamos, aqui, diante de mapas que se detêm no conteúdo manifesto e que envolvem um menor nível de interpretação por parte do pesquisador. A existência de programas de computador que efetuam a análise de material qualitativo constitui uma ferramenta que facilita esse trabalho básico.

(b) Os mapas de identidade incluem, no entanto, aqueles que descrevem estruturas cognitivas bem mais complexas, aproximando-se, por exemplo, dos mapas de schemas, na primeira categorização proposta por Huff (1990). A identificação dessas estruturas subjacentes pode implicar uma elevada carga de interpretação pelo pesquisador e, neste caso, o mapa pode tornar-se bastante complexo, apresentando uma extensa rede de conceitos articulados por múltiplos tipos de associações.

(c) Os mapas que o pesquisador monta são construídos tanto a partir de dados coletados através de entrevistas, no geral semi-estruturadas ou abertas, quanto de fontes escritas, tais como documentos e relatórios, no caso dos estudos organizacionais.

(d) Inexiste um formato mais ou menos padrão ou dominante de organização dos resultados e da sua apresentação gráfica. Ela depende, em larga medida, da criatividade e capacidade do pesquisador de dispor, no espaço, os elementos que estruturam o mapa, de forma a comunicar pronta e efetivamente as informações mais significativas obtidas.

Em um estudo que articula os processos de mudança organizacional, comprometimento e demandas de qualificação para o trabalho, Bastos e Santos (2000b) utilizaram uma estratégia que combina procedimentos oriundos da pesquisa sobre núcleo central das representações sociais (Abric, 1998; Sá, 1996). Desta maneira descreveram o "autoschema" e o schema de "trabalhador comprometido"6 compartilhado por um grupo de trabalhadores de uma empresa de transporte marítimo que tinha acabado de ser privatizada. Em linhas gerais, o procedimento de construção dos mapas envolveu:

1. Uso de entrevistas baseadas em um roteiro semiestruturado que iniciava com questões abertas, para, através de um processo de livre associação, captar os elementos, dos dois schemas investigados - auto-conceito como trabalhador e o conceito de trabalhador comprometido. No primeiro, era solicitado aos trabalhadores que completassem livremente a frase: "como trabalhador eu sou...". No segundo, pedia-se que os trabalhadores evocassem tudo que viesse ao pensamento a respeito do que seria um trabalhador comprometido. As verbalizações eram registradas na ordem da sua evocação. 
Tabela 1.

Características gerais dos diferentes tipos de mapas cognitivos nos estudos organizacionais

\begin{tabular}{|c|c|c|c|}
\hline & Mapas de identidade & Mapas de Categorização & Mapas Causais \\
\hline Objetivo básico & $\begin{array}{l}\text { Avaliar a atenção, associação e } \\
\text { centralidade de conceitos que } \\
\text { estruturam textos, narrativas e } \\
\text { discursos. } \\
\end{array}$ & $\begin{array}{l}\text { Revelar dimensões utilizadas } \\
\text { para criar categorias e taxonomia } \\
\text { cognitivas que estruturam um } \\
\text { domínio de conhecimento. } \\
\end{array}$ & $\begin{array}{l}\text { Identificar relações de influência } \\
\text { e causalidade revelando a } \\
\text { dinâmica do sistema de } \\
\text { argumentação. } \\
\end{array}$ \\
\hline $\begin{array}{l}\text { Pressupostos } \\
\text { assumidos sobre } \\
\text { cognição }\end{array}$ & $\begin{array}{l}\text { "O modo pelo qual as pessoas } \\
\text { percebem o mundo é altamente } \\
\text { influenciado por categorias de } \\
\text { suas linguagens" }\end{array}$ & $\begin{array}{l}\text { "Os indivíduos têm que, } \\
\text { sucessivamente, examinar e } \\
\text { ordenar objetos para buscar } \\
\text { hipotéticos atributos comuns" }\end{array}$ & $\begin{array}{l}\text { "Em um mundo de dados } \\
\text { incompletos, indivíduos fazem } \\
\text { inferências causais que } \\
\text { permitem interpretação." }\end{array}$ \\
\hline $\begin{array}{l}\text { Dados usados e } \\
\text { forma de } \\
\text { obtenção }\end{array}$ & $\begin{array}{l}\text { Textos escritos (relatórios, } \\
\text { documentos, entrevistas } \\
\text { publicadas) } \\
\text { Entrevistas abertas ou pouco } \\
\text { estruturadas sobre o tema }\end{array}$ & $\begin{array}{l}\text { Entrevista semi-estruturada para } \\
\text { identificação de conceitos. } \\
\text { Entrevista estruturada para } \\
\text { identificar a estrutura hierárquica } \\
\text { e as dimensões de julgamento } \\
\text { subjacentes aos processos de } \\
\text { categorização. } \\
\end{array}$ & $\begin{array}{l}\text { Entrevista aberta ou pouco } \\
\text { estruturada para identificação } \\
\text { dos conceitos básicos. } \\
\text { Entrevista estruturada para } \\
\text { identificar os vínculos causais } \\
\text { entre os conceitos }\end{array}$ \\
\hline $\begin{array}{l}\text { Ação inicial } \\
\text { básica para a } \\
\text { construção do } \\
\text { mapa }\end{array}$ & $\begin{array}{l}\text { Análise de conteúdo do material } \\
\text { verbal ou discursivo para } \\
\text { identificação dos conceitos }\end{array}$ & $\begin{array}{l}\text { Identificação e seleção dos } \\
\text { conceitos ou elementos do } \\
\text { domínio investigado (pelos } \\
\text { participantes ou pelo } \\
\text { pesquisador) }\end{array}$ & $\begin{array}{l}\text { Identificação, pelos próprios } \\
\text { sujeitos dos conceitos relevantes } \\
\text { para explicar um evento. }\end{array}$ \\
\hline $\begin{array}{l}\text { Processo } \\
\text { cognitivo básico }\end{array}$ & $\begin{array}{l}\text { Evocação, Lembrança, } \\
\text { Associação }\end{array}$ & Categorização & Explicação, Justificação \\
\hline $\begin{array}{l}\text { Tipo de relação } \\
\text { buscada entre os } \\
\text { conceitos }\end{array}$ & $\begin{array}{l}\text { A me lembra } B \\
A \text { é mais importante que } B\end{array}$ & $\begin{array}{l}\text { A e B são diferentes } \\
\text { A envolve } B \text { e } C\end{array}$ & $\begin{array}{l}\text { A causa B } \\
\text { Se } A \text { é verdade, então B não é } \\
\text { verdadeiro }\end{array}$ \\
\hline $\begin{array}{l}\text { Dimensões } \\
\text { críticas de análise } \\
\text { da representação }\end{array}$ & $\begin{array}{l}\text { Centralidade de determinados } \\
\text { conceitos. } \\
\text { Freqüência e força de evocação. } \\
\text { Justaposição de palavras. } \\
\text { Temas estruturadores. } \\
\end{array}$ & $\begin{array}{l}\text { Distância entre os elementos. } \\
\text { Centralidade do constructo. } \\
\text { Preferência do elemento. } \\
\text { Diferenciação e complexidade / } \\
\text { integração da estrutura. } \\
\end{array}$ & $\begin{array}{l}\text { Explicações causais. } \\
\text { Argumentos justificadores. }\end{array}$ \\
\hline $\begin{array}{l}\text { Formato gráfico } \\
\text { típico }\end{array}$ & $\begin{array}{l}\text { Gráficos estatísticos } \\
\text { Apresentação de conceitos em } \\
\text { espaço unidimensional, ligados } \\
\text { por linhas com sinais que ligam }\end{array}$ & $\begin{array}{l}\text { Figuras tipo árvores que se } \\
\text { desdobram em ramos cada vez } \\
\text { menores na hierarquia. }\end{array}$ & $\begin{array}{l}\text { Redes de associação entre } \\
\text { conceitos (nodos) com o uso de } \\
\text { setas indicando o sentido de } \\
\text { causalidade e de sinais (+ ou -) a } \\
\text { natureza da relação. }\end{array}$ \\
\hline $\begin{array}{l}\text { Metodologia } \\
\text { estruturada mais } \\
\text { utilizada }\end{array}$ & $\begin{array}{l}\text { Técnicas de análise de } \\
\text { conteúdo. } \\
\text { Grande diversidade de formas } \\
\text { de apresentação da estrutura de } \\
\text { relações que emerge da análise }\end{array}$ & $\begin{array}{l}\text { Grid de repertório de G. Kelly } \\
\text { (Reger, 1990a) }\end{array}$ & $\begin{array}{l}\text { Self-Q proposta por Bougon } \\
(1986) \\
\text { CCM - 'comparative causal } \\
\text { maps' (Laukkanen,1992,1998) } \\
\text { SODA desenvolvida por Eden } \\
(1988) .\end{array}$ \\
\hline $\begin{array}{l}\text { Produtos gerados } \\
\text { que são } \\
\text { relevantes para } \\
\text { análises } \\
\text { organizacionais }\end{array}$ & $\begin{array}{l}\text { Identificação dos 'tijolos básicos' } \\
\text { da cognição: conceitos que } \\
\text { estruturam os processos } \\
\text { organizacionais. } \\
\text { Identificação de eixos temáticos } \\
\text { que estruturam o texto, discurso } \\
\text { ou narrativa. } \\
\text { Caracterização de schemas } \\
\text { cognitivos: os 'filtros' utilizados } \\
\text { pelos sujeitos para perceber e } \\
\text { dar sentido aos acontecimentos }\end{array}$ & $\begin{array}{l}\text { Descrição mais aprofundada da } \\
\text { estrutura conceitual que os } \\
\text { sujeitos usam para organizar } \\
\text { seus domínios de conhecimento. } \\
\text { Hierarquias e taxonomias que os } \\
\text { atores organizacionais utilizam } \\
\text { para localizar e dar sentido a } \\
\text { elementos do seu contexto. }\end{array}$ & $\begin{array}{l}\text { Redes de causalidades } \\
\text { construídas para explicar um } \\
\text { evento organizacional. } \\
\text { Seqüências de ações e } \\
\text { condições que conduzem a } \\
\text { produtos ou resultados } \\
\text { desejados. } \\
\text { Lógica que embasa decisões } \\
\text { sobre cursos alternativos de } \\
\text { ação para atingir metas tidas } \\
\text { como relevantes. }\end{array}$ \\
\hline
\end{tabular}


2. O material verbal evocado foi analisado a partir de seus conteúdos, criando-se categorias descritivas e abrangentes da sua variabilidade.

3. A partir da freqüência de evocação (número de vezes que a idéia apareceu na amostra) e a ordem ou força de evocação (uma média aritmética da ordem em que havia sido mencionada entre todos os sujeitos que mencionaram a idéia) foi possível construir gráficos, que mapeiam o conjunto de idéias dos sujeitos, identificando os conteúdos que integram o núcleo central (entre as categorias mais citadas, as que foram citadas com maior força).

4. Os mapas informam, assim, aqueles conteúdos que são centrais e os periféricos, permitindo explorar a questão da pesquisa: o quanto elementos que definem um trabalhador comprometido são utilizados na construção da identidade do próprio trabalhador. Esses mapas dispõem os conceitos em um espaço definido por dois eixos (frequiência e força), permitindo identificar as idéias que se localizam em cada quadrante do espaço cartesiano.

\section{b) Mapas de categorização}

Essa segunda família de mapas busca, especialmente, descrever como os indivíduos organizam ou estruturam o seu conhecimento e, portanto, usam o processo de categorização. Ela se apóia nos seguintes pressupostos: o pensamento requer um resgate da memória organizada; o processo de categorização - modificação de velhas categorias e criação de novas - está envolvido na aprendizagem; e que o significado de qualquer conceito emerge do seu contraste com outros conceitos.

Nesta família de mapas encontramos uma metodologia extremamente bem estruturada que tem como base a teoria dos construtos pessoais de G. Kelly ${ }^{7}$. Mais especificamente, nos estudos organizacionais, utiliza-se a técnica denominada "grid de repertório" que, em suas linhas gerais, fornece percepções dos indivíduos sobre os elementos ao longo de dimensões ou construtos que são auto-gerados. Uma descrição dos procedimentos envolvidos é fornecida por Reger (1990a). Três estágios estão envolvidos na aplicação do grid de repertório:

- No primeiro estágio, os elementos são selecionados, quer a partir de considerações teóricas, quer a partir dos próprios sujeitos, quando o pesquisador não se sente seguro quanto aos elementos relevantes a incluir. Tais elementos podem ser pessoas, objetos ou organizações, ou propriedade de pessoas e objetos. Eles constituem o terreno a ser mapeado.

- No estágio seguinte, tais elementos são apresentados ao sujeito para classificá-los, hierarquizá-los e compará-los, julgamentos que permitirão a identificação dos construtos relevantes utilizados pelo sujeito para fazer tais julgamen- tos. Há várias maneiras para eliciar tais construtos, apresentado tríades de conceitos, ou todos de uma só vez para que o sujeito escolha os dois mais similares.

- A etapa final envolve a composição de uma matriz com os dados (construtos e avaliações). Esses dados podem ser analisados através de um diversificado conjunto de técnicas - geométricas, quantitativas ${ }^{8}$ e qualitativas - para representar o sistema de construtos do sujeito. A análise de conteúdo envolve: a distância entre elementos (uma medida de similaridade percebida), a centralidade do construto (a importância de um construto em relação aos demais) e a preferência do elemento (a desejabilidade).

Reger (1990b) desenvolveu uma pesquisa bem representativa do uso deste tipo de mapa, identificando dimensões cognitivas utilizadas por gerentes para compreender seu posicionamento competitivo no mercado bancário. Observou que gerentes de diferentes empresas, em um mesmo ambiente competitivo, revelam baixo nível de concordância sobre as dimensões estratégicas centrais. E, interessantemente, identificou, para o grupo total de gerentes, que as dimensões salientes não eram congruentes com aquelas apontadas pelos pesquisadores sobre estratégia organizacional, indicando que estrategistas e pesquisadores trabalham sob diferentes quadros de referência ao solucionarem problemas estratégicos.

\section{c) Mapas causais}

Nos estudos organizacionais, os mapas causais são os mais largamente usados, o que leva a muitas vezes serem tomados como sinônimos de mapas cognitivos (Laukkanen,1998). Em parte, pela primazia em se compreender as condições que geram decisões de sujeitos singulares, face à necessidade de compartilhamento de visões e coordenação de cursos de ações. Essa necessidade, tão central na constituição do fenômeno organizacional, revela-se básica para a análise das práticas gerenciais e fundamental para o êxito de qualquer empreendimento coletivo.

Os mapas causais fornecem, ainda, uma compreensão dos vínculos que os indivíduos estabelecem entre ações e resultados ao longo do tempo, assim como os pressupostos subjacentes aos julgamentos de que uma ação levará a um resultado esperado. Face a isso, Bougon (1983) afirma que o mapa causal, ao revelar a estrutura conceitual da pessoa, "pode ser interpretado como um mapa da sua estrutura motivacional, por expor as finalidades, métodos, conflitos e contextos de sua compreensão" (p. 181).

As três principais estratégias metodológicas disponíveis para a construção de mapas causais estão sintetizadas na Tabela 2, como base para discutirmos suas especificidades.

A primeira reporta-se ao modelo desenvolvido por Bougon (1983) ${ }^{9}$ que traz como elemento singular, sobretu- 
Tabela 2.

Elementos que singularizam as três principais estratégias de construção de mapas causais.

\begin{tabular}{|c|c|c|c|}
\hline & Bougon (1983) & Laukkanen (1998) & Eden (1988) \\
\hline Coleta dos dados & $\begin{array}{l}\text { Self-Q (uma técnica de auto } \\
\text { questionamento) }\end{array}$ & $\begin{array}{l}\text { Dados documentais e/ou } \\
\text { entrevistas - inicialmente não- } \\
\text { estruturada. }\end{array}$ & $\begin{array}{l}\text { Dados documentais e/ou } \\
\text { entrevistas. }\end{array}$ \\
\hline Análise dos dados & $\begin{array}{l}\text { O próprio sujeito participa em } \\
\text { várias etapas: identificação de } \\
\text { conceitos; avaliação da } \\
\text { congruência entre a idéia } \\
\text { expressa e a formulação pelo } \\
\text { pesquisador; o sentido do mapa } \\
\text { construído }\end{array}$ & $\begin{array}{l}\text { Identificação dos temas âncora: } \\
0 \text { desenvolvimento de um } \\
\text { vocabulário padrão - categorias } \\
\text { que agrupam sinônimos e } \\
\text { permitem comparar o material. } \\
\text { Criação de matriz de dados com } \\
\text { as relações causais. } \\
\text { Identificação de clusters de } \\
\text { sujeitos segundo a similaridade } \\
\text { dos conceitos enunciados. } \\
\text { Medidas quantitativas: distância, } \\
\text { complexidade, unidades } \\
\text { centrais, similaridade etc. }\end{array}$ & $\begin{array}{l}\text { Identificação dos construtos: } \\
\text { frases que devem preservar a } \\
\text { linguagem "natural". } \\
\text { Formulação de conceitos } \\
\text { bipolares: opostos psicológicos, } \\
\text { conforme teoria dos construtos } \\
\text { pessoais de Kelly. } \\
\text { Três tipos/níveis de conceito: } \\
\text { objetivo/metas - opções } \\
\text { estratégicas - opções } \\
\text { potenciais. } \\
\text { Identificação de clusters - } \\
\text { conjuntos de nós relacionados. }\end{array}$ \\
\hline Recurso tecnológico & Não disponível & $\begin{array}{lcr}\text { Software } & \text { CMPA2 } & \text { (não- } \\
\text { comercial). } & \text { Não permite a } \\
\text { construção } & \text { gráfica dos } \\
\text { resultados. } & & \\
\end{array}$ & $\begin{array}{l}\text { Software 'Decison Explorer' } \\
\text { (comercial). } \\
\text { Permite a disposição dos dados } \\
\text { na forma de mapas. }\end{array}$ \\
\hline Formato gráfico & $\begin{array}{l}\text { Os conceitos são dispostos em } \\
\text { um polígono e uma teia central } \\
\text { de relações expressa os } \\
\text { vínculos causais entre eles. }\end{array}$ & $\begin{array}{l}\text { Nodos (conceitos) ligados por } \\
\text { setas que indicam vínculo } \\
\text { causal. }\end{array}$ & $\begin{array}{l}\text { Nodos (conceitos) ligados por } \\
\text { setas que indicam vínculo } \\
\text { causal. Conceitos organizados } \\
\text { em uma hierarquia que leva } \\
\text { aos objetivos (topo do mapa). }\end{array}$ \\
\hline
\end{tabular}

do, a técnica utilizada para extrair e relacionar os conceitos que integram o mapa. A denominada $S e l f-Q$ (técnica de autoquestionamento) estrutura um processo para eliciar o material cognitivo, minimizando a interferência do entrevistador e transferindo para o entrevistado a maior parte da iniciativa, direcionamento e checagem da validação. No seu conjunto, ela envolve em torno de quatro sessões de entrevistas, que são sinteticamente descritas pelo próprio autor:

\begin{abstract}
Na primeira entrevista, eu coleto conceitos nãodiretivamente. Na segunda entrevista, eu verifico os conceitos e noções coletadas na primeira. Eu também obtenho sua distribuição em diferentes classes, assim como o seu ordenamento por importância. Na terceira entrevista eu obtenho as relações causais entre os conceitos. E na quarta entrevista, eu verifico se o mapa causal faz sentido para os próprios respondentes (p. 182).
\end{abstract}

Uma segunda metodologia foi desenvolvida por Mauri Laukkanen, por ele denominada CCM (Comparative Causal Mapping) por se voltar, especialmente, para a análise comparativa -entre sujeitos de um mesmo grupo, entre di- ferentes grupos de sujeitos ou entre diferentes momentos ao longo do tempo - das estruturas de crenças dos gestores sobre a efetividade dos seus comportamentos.

A partir de dados qualitativos - coletados através de entrevistas ou mesmo de documentos - há o trabalho de análise de conteúdo que leva à identificação dos temas âncoras, a partir dos quais são levantadas as percepções dos sujeitos sobre seus antecedentes causais. Para esse processo, a metodologia envolve o uso de um software específico - o CMPA $2{ }^{10}$. Alguns passos importantes da metodologia são sintetizados a seguir:

(a) Criação de categorias que levam a um vocabulário padrão, elo crítico de todo o processo, já que é a condição para a comparação e integração de enunciados que trazem a variabilidade da linguagem natural. Esta etapa da análise é qualitativa.

(b) Construção de uma matriz de dados, envolvendo conceitos e relações de causalidade entre pares de conceitos. Como uma planilha, ela permite um conjunto sofisticado de indicadores que são base para as comparações entre sujeitos ou entre clusters de sujeitos. 
(c) Existe a possibilidade de calcular vários indicadores quantitativos: uma medida da complexidade cognitiva do discurso (número de unidades causais enunciadas); índices de distância do sujeito em relação ao conjunto; a força de termos centrais e unidades causais centrais (Core Causal Units); níveis de similaridade e dissimilaridade entre gerentes.

(d) A construção gráfica do mapa pode ser importante nos relatórios finais para fornecer, de forma visual e global, uma visão dos padrões de pensamento relacionados ao domínio investigado. Para tanto, essa etapa deve envolver outros programas gráficos, pois o CMPA2 não possui esses recursos.

A terceira metodologia origina-se da linha de trabalho desenvolvida por Colin Eden e associados ${ }^{11}$, sendo denominada SODA (Strategic Options Development Analysis). Volta-se, especialmente, para fornecer insumos à escolha de cursos de ações julgados estratégicos pela organização. Possui, portanto, o caráter de uma metodologia de solução ou modelagem de problemas organizacionais, como bem assinala Pidd (1998), ao classificá-la como uma técnica soft de modelagem de situações problema.

A técnica trabalha aplicando as seguintes regras:

(a) Uma explicação de um problema é quebrada em seus elementos constituintes - frases normalmente distintas de 10 -12 palavras que retêm a linguagem da pessoa provedora da explicação. Esses são tratados como conceitos distintos que são reconectados para representar, então, a explicação em um formato gráfico. Isto revela o padrão de raciocínio sobre um problema que, de certo modo, o texto linear não permite.

(b) Um par de frases pode ser unido em um único conceito, quando a pessoa provê um contraste significante com outro, isto é, quando o contraste permite ao usuário construir e reter um significado melhor da outra frase. Estas frases formam um construto único: o significado é retido por contraste.

(c) As frases que representam conceitos distintos são organizadas de acordo com os vínculos entre eles para formar uma hierarquia de meios e fins. Isto envolve decidir sobre o status de um conceito relativo ao outro, de acordo com uma hierarquia de três níveis: aqueles que expressam objetivos devem vir no topo do mapa. As escolhas estratégicas - "pivôs ao redor dos quais o mapa está centrado" (Pidd, 1988, p. 149) são conceitos cujos pares implicam em conseqüências de longo prazo, elevado custo ou que são irreversíveis. As opções preferenciais são conceitos enunciados de forma imperativa, com a opção preferida como o primeiro pólo.

(d) As setas que ligam os conceitos incorporam um sinal positivo ou negativo para indicar influência direta ou indireta. O sinal negativo indica que o segundo pólo de um conceito-meio está psicologicamente vinculado ao primeiro pólo de um conceito fim.

(e) Coerente com a sua orientação tecnológica - um instrumento para diagnóstico e intervenção em decisões organizacionais - o software Decision Explorer facilita o processo de ordenar no espaço os conceitos, as relações causais e as linhas de argumentação que os entrevistados estabelecem entre eles.

(f) Dos mapas individuais emerge um "mapa estratégico" com o qual as pessoas possam identificar-se, levando o grupo a comprometer-se com uma linha de ação apropriada. No processo global da consultoria, ela se articula a seminários que buscam, partindo dos mapas individuais e do coletivo, descobrir idéias comuns sobre como enfrentar problemas e implementar decisões que contribuam para a melhoria organizacional.

Um exemplo de pesquisa conduzida no Brasil utilizando mapas causais encontramos no trabalho de Lindner (1998), que utiliza os mapas cognitivos como uma técnica para estruturar problemas complexos, aplicando-a como uma primeira etapa no processo de avaliação de desempenho de uma cooperativa agropecuária ${ }^{12}$. Em um conjunto de entrevistas com os quatro "decisores" (gerentes de diferentes áreas), foram levantados: a) elementos primários de avaliação - EPA's - que consistem em pontos considerados importantes pelos sujeitos para o problema em questão; esses elementos são levantados de forma mais livre e espontânea e eram orientados para a ação; b) identificação dos conceitos, segundo a proposta de Ackerman e Eden, envolvendo opostos psicológicos; c) a hierarquização dos conceitos em termos de meios - fins; d) estabelecimento das linhas de influência. Aplicada a referida técnica com cada caso individual, os mapas foram agregados pelo pesquisador e apresentados para a discussão com o grupo participante, segundo diretrizes propostas por Bougon (1992). Todo esse processo gerou o que o autor denomina "pontos de vista fundamentais" - PVF's, que representam uma vontade consensual entre os atores envolvidos no processo de tomada de decisão. A riqueza das informações obtidas no nível individual expressa em diferentes mapas cognitivos foi considerada uma etapa fundamental para o processo de avaliação geral, por permitir a negociação, gerar aprendizado e conhecimento, garantindo, assim, um melhor entendimento por parte dos atores.

\section{À guisa de conclusão: questões que cercam o uso dos "mapas cognitivos" na pesquisa organizacional}

Diante de estratégias tão diversificadas utilizadas para descrever, organizar e representar cognições dos atores organizacionais, todas sob o rótulo de 'mapa cognitivo', torna-se complexa a tarefa de fazer avaliações comparativas. 
Esse desafio torna-se maior, pela novidade das propostas, pelo ainda incipiente número de investigações que avaliam os seus resultados e, sobretudo, pela dificuldade em se utilizarem os mesmos parâmetros de validade e fidedignidade usados frente a técnicas e instrumentos de pesquisa mais convencionais.

O mapeamento cognitivo é uma estratégia metodológica especialmente voltada para explicitar os processos de construção de sentido e a estruturação de conhecimento (schemas), tanto entre indivíduos, como entre grupos e organizações. Lida, preferencialmente, com relatos verbais ou discursos e busca preservar, ao máximo, a linguagem natural dos participantes. Portanto, grosso modo, pode ser inserido no grupo de estratégias de pesquisa qualitativas e intensivas, apesar de algumas técnicas permitirem e trabalharem indicadores quantitativos a partir do material qualitativo coletado inicialmente.

A diversidade de técnicas apresentada anteriormente advém, em parte, da própria pluralidade de processos e estruturas cognitivas que são postulados para compreender um vasto conjunto de problemas, decisões, domínios e realidades que configuram cada contexto organizacional específico. Alguns pontos parecem consensuais entre os autores que, envolvidos com o seu uso, avaliam a contribuição dessa ferramenta metodológica.

Primeiro, há um envolvimento dos sujeitos com o próprio processo de construção dos mapas. Nesse sentido, o mapeamento cognitivo permite ao sujeito refletir sobre a sua própria visão e conhecimento acumulado sobre um determinado domínio, constituindo um processo de aprendizado pessoal e coletivo.

Segundo, excetuando-se os mapas de identidade, há tentativas de estruturar o processo de construção dos mapas, configurando metodologias específicas. Em todas elas, no entanto, pode-se perceber alguns princípios norteadores: a coleta de dados menos diretiva, a preservação da linguagem natural, a importância do processo de análise de conteúdo e criação das categorias que estruturam os mapas.

Terceiro, há dificuldade em se atender aos parâmetros clássicos de validade ${ }^{13}$. Os mapas não deixam de sofrer influência do mapeador que trabalha sob o pressuposto da inexistência de critérios externos que possam ser tomados como parâmetros independentes da visão dos atores expressa no mapa. A replicabilidade dos mapas também é difícil, sobretudo naqueles tipos que envolvem maior carga interpretativa e maior afastamento do material verbal coletado, o que se deve, em parte, ao fato de ele surgir de um processo interativo.

Quarto, como nos chama a atenção Blood (1998), o fato de os métodos de mapeamento gerarem dados interativamente pode contribuir para que os mapas sejam afetados pelos processos de racionalização post hoc que podem refletir teorias esposadas pelos sujeitos. Esse problema seria minimizado quando sessões mais longas e intensivas fossem utilizadas para coletar e discutir o tratamento dos dados. O mesmo autor aponta, ainda, para um outro limite importante. Os mapas lidam com o conhecimento explícito, sendo severamente limitados no acesso ao conhecimento tácito, tido como garantido e difícil de ser verbalizado. Neste particular, tal dificuldade não seria privativa do mapeamento e sim de todas as metodologias de pesquisa sócio-comportamentais.

Finalmente, vale destacar reflexões feitas por Nicollini (1999) embasadas na pesquisa em que comparou, empiricamente, as metodologias de mapas cognitivos (modelo de Bougon, 1983) e representação social (segundo proposta de S. Moscovici), como estratégias para representar cognições de gestores em uma empresa de engenharia do setor elétrico. Reconhecendo que ambos os métodos são efetivos no sentido de revelarem, com diferenças, alguns aspectos da cognição organizacional, é assinalado que os mesmos simultaneamente escondem outras dimensões que podem, potencialmente, ser mais significativas. As dificuldades de ambas as estratégias decorrem dos próprios princípios epistemológicos que as embasam - o dualismo entre realidade e pensamento e este como um espelho daquela. Para o autor, as representações sociais e os mapas causais precisam ser reconceitualizados como produções discursivas e repertórios lingüísticos dentro de um processo geral de ordenação e construção de sentido. Em síntese, o autor argumenta em favor da superação de uma perspectiva "representacionista", assumindo que as pessoas não vivem em um mundo de representações e sim em um mundo de produção de discursos e de jogos de linguagem, como afirmam os filósofos da linguagem. Ou seja, as representações e os mapas não são puros processos de pensamento individuais, mas sim práticas discursivas que se relacionam ao contexto material, simbólico e social em que ocorrem. Assim, a construção de sentido dos atores envolve aquilo que eles dizem, assim como o que eles fazem, ou não fazem, e os artefatos que utilizam (Nicolini, 1999).

Quando são retomados os pressupostos e idéias básicas que fundamentam uma perspectiva cognitivista para o exame do fenômeno organizacional, podemos verificar que o mapeamento cognitivo revela-se uma das estratégias metodológicas mais congruentes com uma epistemologia social construtivista e que ela, necessariamente, não se vincula a uma concepção dualista que separa mente/cognição de ação. Essa base construtivista revela-se, inclusive, nos elementos intrínsecos que definem a maior parte das metodologias aqui examinadas, quando observamos que os participantes da pesquisa são ativos na construção do pró- 
prio conhecimento (mapa) gerado pelo pesquisador, não sendo apenas fornecedores de informações ou dados. Por sua flexibilidade no tocante a trabalhar com múltiplos modelos de cognição e de cognição social hoje disponíveis, o uso de mapas cognitivos pode ser adequado a uma vasta gama de questões nas quais o conhecimento ou pensamento dos atores desempenha importante papel nas suas decisões e ações, cerne dos processos de organizar e da visão de organização como sistemas interpretativos ou construções sociais. Examinando-se os produtos gerados pelo uso dessa estratégia metodológica, podemos perceber que, mais do que uma ferramenta de apoio ou suporte a decisões, faz sentido que o termo mapa cognitivo seja usado por Weick e Bougon (1986) como uma metáfora para definir a própria organização.

\section{Referências}

Abric, J. C. (1994). L'organisation interne des representations socials: systeme central et systeme peripherique. In Ch. Guimelli (Org.), Structures et transformations des representations socials (pp. 73-84). Lausanne: Delachaux et Niestlé.

Barnard, C. I. (1979). As funções do executivo. São Paulo: Atlas. (Texto original publicado em 1938).

Bastos, A. V. B. (2000a). Organização e cognição: o que emerge desta interface?. In S. B. Rodrigues \& M. P. Cunha (Orgs.), Estudos organizacionais: novas perspectivas na Administração de Empresas (pp.173-211). São Paulo: Iglu.

Bastos, A. V. B., \& Santos, M. V. (2000b). O 'schema'de trabalhador comprometido: elemento definidor da identidade no trabalho [Resumo]. In Sociedade Brasileira de Psicologia (Org.), XXX Reunião Anual de Psicologia (p. 222). Brasília: Autor.

Blood, R. P. (1998). Charting organizational learning: a comparison of multiple mapping techniques. In C. Eden \& J.-C.Spender (Orgs.), Managerial and organizational cognitons - theory, methods and research (pp.210-30). London: Sage.

Bougon, M. (1983). Uncovering cognitive maps: The Self-Q Technique. In G. Morgan (Org.), Beyond method (pp.160-72). Newbury Park: Sage.

Bougon, M., Weick, K., \& Binkhorst, D. (1977). Cognition in organization: an analysis of the Utrech Jazz Orchestra. Administrative Science Quarterly, 22, 606-39.

Burrell, G., \& Morgan, G. (1982). Sociological paradigms and organizational analysis. London: Heinemann Educational Books.

Cossette, P., \& Audet, M. (1994). Qu'est-ce qu'une carte cognitive? In P. Cossette (Org.), Cartes cognitives et organisations (pp.13-33). Quebec: Les Presses de l'Únivesité Laval et les Éditions ESKA,

Csányi, V. (1995). The biological bases of cognitive maps. In E. Laszlo et al. (Orgs.), The evolution of cognitive maps - new paradigms for the twenty-first century. Amsterdam: Gordon and Breach.

Eden, C. (1988). Cognitive mapping. European Journal of Operational Research, 36, 1-13.

Fiol, C. M., \& Huff, A. (1992). Maps for managers: where are we? Where we go from here? Journal of Management Studies, 29(3), 267-85.

Grandesso, M. A. (2000). Sobre a reconstrução do significado: uma análise epistemológica e hermenêutica da prática clínica. São Paulo: Casa do Psicólogo.

Huff, A. S. (1990). Mapping strategic thought. In A. S. Huff (Org.), Mapping strategic thought (pp. 11-49). Chichester: Wiley \& Sons.
Ilgen, D. R., \& Klein, H. J. (1988). Organizational Behavior. Annual Review of Psychology, 40, 327-51.

Jenkis, M. (1998). The theory and practice of comparing causal maps. In C. Eden \& J.-C. Spender (Orgs.), Managerial and organizational cognitons - theory, methods and research (pp.231-250). London: Sage.

Katzell, R. A. (1991). Contemporary meta-trends in industrial and organizational psychology. In M. D. Dunnette \& L. M. Hough (Orgs.), Handbook of industrial and organizational psychology (2 $2^{\text {nd }}$. ed., vol. 2, pp. 1-89). Palo Alto: Consulting Psychologists.

Laszlo, E., Masulli, I., Artigiani, R., \& Csányi, V. (1995). The evolution of cognitive maps - new paradigms for the twenty-first century. Amsterdam: Gordon and Breach.

Laukkanen, M. (1992). Comparative cause mapping of management cognitions. Helsinki: Helsinki School of Economics.

Laukkanen, M. (1998). Conducting causal mapping research: opportunities and challenges. In C. Eden \& J.-C.Spender (Orgs.), Managerial and organizational cognitons - theory, methods and research (pp.168191). London: Sage.

Lindner, G. H. (1998). Avaliação de uma cooperativa agropecuária orientada para o seu aperfeiçoamento utilizando a metodologia multicritério em apoio à decisão. Dissertação de Mestrado nãopublicada. Universidade Federal de Santa Catarina, Florianópolis.

Lord, R.G., \& Maher, K. J. (1989). Cognitive processes in industrial and organizational psychology. In C. L. Cooper \& I. Robertson (Orgs.), International review of industrial and organizational psychology (pp. 49-91). New York: John Wiley \& Sons.

Lord, R.G., \& Maher, K. J. (1991). Cognitive theory in industrial and organizational psychology. In M. D. Dunnette \& L. M. Hough (Orgs.), Handbook of industrial and organizational psychology ( $2^{\text {nd }}$ ed., vol 2, pp. 1-20; 34-47). Palo Alto: Consulting Psychologists Press.

Lyddon, W. J. (1997). Formas e facetas da Psicologia Construtivista. In R. A. Neimeyer \& M. J. Mahoney (Orgs), Construtivismo em Psicoterapia (pp. 60-78). Porto Alegre: Artes Médicas.

Mahoney, M. J. (1998). Processos humanos de mudança: as bases científicas da psicoterapia. Porto Alegre: Artmed.

March, J., \& Simon, H. (1981). Teoria das organizações. Rio de Janeiro: Editora da Fundação Getúlio Vargas. (Texto originalmente publicado em 1956).

Morgan, G. (1996). Imagens da organização. São Paulo: Atlas.

Nicolini, D. (1999). Comparing methods for mapping organizational cognition. Organization Studies, 20(5), 833-860.

Pearce, W. B. (1996). Novos modelos e metáforas comunicacionais: a passagem da teoria à prática, do objetivismo ao construcionismo social $\mathrm{e}$ da representação à reflexibidade. In D. Schnitman (Org.), Novos paradigmas, cultura e subjetividade (pp. 172-183). Porto Alegre: Artes Médicas.

Pidd, M. (1998). Modelagem empresarial: ferramentas para tomada de decisão. Porto Alegre: Bookman.

Porac, J. F., Meindl, J. R., \& Stubbart, C. (1996). Introduction. In J. Porac, J. Meindl \& C. Stubbart (Orgs.), Cognition within and between organizations (pp. ix-xxiii). Thousand Oaks: Sage.

Reger, R. K. (1990a). The repertory Grid Technique for eliciting the content and structure of cognitive constructive systems. In A. S. Huff (Org.), Mapping strategic thought (pp. 301-309). Chichester: Wiley \& Sons.

Reger, R. K. (1990b). Managerial thinking, structures and competitive positioning. In A. S. Huff (Org.), Mapping strategic thought (pp.7188). Chichester: Wiley \& Sons.

Rousseau, D. (1997). Organizational Behavior in the new era. Annual Review of Psychology, 48, 515-546.

Sá, C. P. (1996). Núcleo das representações sociais. Petrópolis: Vozes. 
Simon, H. (1979). Comportamento administrativo. Rio de Janeiro: Editora da Fundação Getúlio Vargas. (Texto originalmente publicado em 1945)

Swan, J. (1997). Using cognitive mapping in management research: decisions about technical innovation. British Journal of Management, 8, 183-198.

Swan, J., \& Newel, S. (1998). Making sense of technological innovation: the political and social dynamics of cognition. In C. Eden \& J.C.Spender (Orgs.), Managerial and organizational cognitons - theory, methods and research (pp.108-129). London: Sage.

Tenbrunsel, A. E., Galvin, T. L., Neale, M. A., \& Bazerman, M. H. (1996). Cognitions in organizations. In S. Clegg, C. Hardy \& W. Nord Orgs.), Handbook of organization studies (pp.148-174). London: Sage.
Walsh, J. P. (1995). Managerial and organizational cognition: notes from a trip down memory lane. Organization Science, 6(3), 280-321.

Weick, K. E. (1973). Psicologia Social da Organização. São Paulo: Edgard Blücher.

Weick, K. E. (1993). Sensemaking in organizations: small structures with larges consequences. In J. K. Murnighan (Orgs.), Social psychology in organizations (pp.10-37). Englewood Cliffs: Prentice-Hall.

Weick, K. E., \& Bougon, M. G. (1986). Organizations as cognitive maps: charting ways to success and failure. In H. P. Sims Jr., D. A. Gioia (Orgs.), The Thinking organization: Dynamics of organizational social cognition (pp. 102-135). San Francisco: Jossey-Bass Publishers.

Wilpert, B. (1995). Organizational behavior. Annual Review of Psychology, $46,59-90$.

\section{Notas}

1 Estamos, aqui, diante de mais um conceito usual nas ciências sociais que guarda uma multiplicidade de significados e usos. É extensa a literatura que discute uma perspectiva construtivista para o entendimento dos processos que articulam os indivíduos e seus contextos. Para uma visão geral e o acesso aos conceitos básicos e às diferentes origens e tipos de construtivismo é interessante a leitura de Pearce (1996), Mahoney (1998) e Grandesso (2000).

2 Em um trabalho que procura integrar as contribuições dos diversos capítulos do Handbook of Industrial and Organizational Psychology, o autor inclui, ao lado da perspectiva cognitivista, outras macro tendências a exemplo de: a perspectiva desenvolvimentista, a busca de modelos complexos, o tratamento de diferentes níveis de análise, a diversidade da força de trabalho, os grupos de trabalho. Na perspectiva cognitiva, ressalta clássicos temas (solução de problemas, tomada de decisão, avaliação de desempenho, liderança, fatores humanos, comportamento do consumidor). Outros temas, contudo, são também fortemente tocados pela agenda cognitiva: mensuração, treinamento, comprometimento organizacional, motivação, escolha do trabalho e aprendizagem.

3 Os mapas cognitivos são, também, importantes ferramentas de intervenção e modelagem de processos organizacionais. Tal dimensão não será retomada no presente texto.

4 Essa consideração nos permite introduzir a diferença entre mapas e territórios. Um - o território - constituído das coisas e dos eventos; outro - o mapa, de palavras sobre eventos e coisas. A atividade de simbolizar permite ao homem mapear o seu território.

5 Aqui, os autores se apóiam na distinção entre 'cognitive map' e 'strip map'. Os 'strip maps' seriam rotas aprendidas, onde cada ponto, de forma seqüencial, é associado a uma resposta apropriada, sem um componente estrutural que assegure a flexibilidade de não seguir um padrão fixo de rota.

6 Nesse mesmo estudo, foram exploradas outras estruturas cognitivas usadas pelos sujeitos: a noção de 'trabalhador qualificado'e de 'empresa moderna', schemas que podem ser úteis para a compreensão de como os trabalhadores estão lidando e dando significado ao conjunto de transformações por que passam as organizações e o mundo do trabalho em geral.

7 Eden (1988) faz uma sintética descrição do uso dos mapas a partir do referencial teórico de Kelly. O autor destaca três postulados da teoria dos construtos pessoais como importantes para fundamentar o seu uso nos contextos organizacionais: individualidade (cada pessoa desenvolve um conjunto de construtos singular, com o qual dá sentido às suas experiências, em função de que cada indivíduo percebe coisas distintas naquilo que poderia ser considerado uma mesma situação); sociabilidade (a idéia de que as pessoas são capazes de compreender construtos dos outros e afetar a sua própria construção em um outro indivíduo, o que fornece a base para os processos de interação social); e, comunalidade (as pessoas podem compartilhar construtos gerando a possibilidade de criar consenso e comprometimento com uma ação e criando uma forma comum de construção de eventos futuros). 
8 Técnicas estatísticas tais como análise fatorial, análise discriminante, análise de cluster e multidimensional scaling têm sido utilizadas por pesquisadores, embora, neste ponto, se afastem do referencial desenvolvido por Kelly.

9 Sua metodologia foi aplicada inicialmente em estudo dos conceitos e explicações causais utilizados pelos músicos da Utrech Jazz Orchestra para a qualidade do seu desempenho (Bougon, Weick \& Binkhorst, 1977). Uma descrição mais pormenorizada da metodologia encontra-se em Bougon (1983).

${ }^{10}$ Os principais aspectos metodológicos e técnicos envolvidos na construção desses mapas estão descritos em Laukkanen (1992, 1998). O CMAP2 é um software não-comercial criado pelo autor e disponibilizado para pesquisadores interessados em seu uso.

${ }^{11}$ Entre outros, o texto de Eden (1988) faz uma interessante apresentação da tecnologia e dos seus vínculos com a teoria cognitiva.

${ }^{12} \mathrm{O}$ trabalho envolve o uso do modelo multicritério para avaliar os impactos das decisões. Interessa-nos, no momento, apenas a etapa de construção dos mapas cognitivos dos principais decisores.

${ }^{13}$ Há reduzidos estudos sobre validade e apenas para o grid de repertório ela é bem estabelecida (Swan, 1997). Jenkins (1998) destaca a base estruturada e rigorosa para assegurar a confiabilidade como um dos pontos fortes da metodologia proposta por M. Bougon.

Antonio Virgílio Bittencourt Bastos, doutor em Psicologia pela Universidade de Brasília, é Professor Titular do Departamento de Psicologia e do Núcleo de Pós-Graduação em Administração - NPGA da Universidade Federal da Bahia, Salvador, BA. Pesquisador Associado do Centro de Estudos Interdisciplinares para o Setor Público - ISP/UFBa. Endereço para correspondência: Av. Garibaldi, 2592/1401, Rio Vermelho, 41.950-176, Salvador, Bahia. Tel.: (71) 237-1018/18. E-mail: virgilio@ufba.br ; antonio_virgilio@uol.com.br. 